\title{
BENEFITS OF VIDEOS IN JOB ADVERTISMENTS FOR POTENTIAL CANDIDATES
}

Tom Sander ${ }^{1}$, Dr.cs.admin/ Professor; Biruta Sloka², Dr.oec./ Professor; Ieva Puke ${ }^{3}$, Mg.sc.admin./ Doctoral student and Anastasija Vilcina ${ }^{4}$, Dr.oec./ Professor ${ }^{1}$ University of Ludwigshafen, Germany ; ${ }^{2,3}$ University of Latvia; ${ }^{4}$ Latvia University of Life Sciences and Technology

\begin{abstract}
This paper investigates the use of videos in job advertisements. This is very important for companies to differentiate their job advertisement from other companies and to attract potential candidates to apply. Organizations need new opportunities to attract individuals to join their organisation. The member of the organization influences the value of the organization. That means organizations are interested to have the most suiTable member to be successful and to have a competitive advantage with the new member. Trends of online video watching prove video to be the most preferred way of content consumption. The paper identifies the values of videos in job advertisement for employment seeking individuals. The research asked up to 319 individuals about the usefulness of videos in job advertisements and benefit for potential candidates with the content of videos in job advertisement. The advantage of videos is the content and to provide additional information. The authenticity of the videos provides a realistic job preview. The result of the paper is that job advertisements with videos are more beneficial for potential candidates. The results support companies to optimize their job advertisements.
\end{abstract}

Key words: recruiting, job advertisement, video, signalling theory, social media.

JEL code: M54.

\section{Introduction}

Many companies have started to improve the job advertisements with videos. The changes in the marketing tools and marketing related technologies provides new opportunities for companies (Li \& Bernoff, 2011). Online usage of video content is becoming everyday habit. ComScore reports shows that in March 2016 alone 233898000 people were watching video content in US, from desktop computers comparing to 191482000 people in August 2015 (ComScore U.S. Desktop Online Video Rankings). Adding up the numbers, more than half of all video viewing is happening on mobile (Ooyala's 2017 Global Video Index). Video proves to be one of the most preferred ways of consuming content. The data (The Animoto Online and Social Video Marketing Study, 2015) shows that businesses with video marketing strategies have an elevated brand perception as a result: respondents say that they want more video marketing on web, social networks and email: one in four consumers lose interest in company, if it does not have video. Four times as many consumers would rather watch a video than read about a product or service, $84 \%$ of respondents say they have liked a company video on their newsfeed. These findings show that people are taking action after watching video advertising. Accordingly, spending on online video advertising is increasing. eMarketer expects US digital video ad spending will see double-digit growth annually through 2020. Brands are spending more than half of their digital budgets on video: $56 \%$ will be allocated to digital video in 2017, US marketers have confirmed in the survey (Digital Content Newfronts: Video Ad Spend Study", 2017).

The research investigates the use of videos in job advertisements in the internet and asked individuals about the advantages for potential applicants. The power of information and access to information is critical for business success. The knowledge economy need access and maintenance of knowledge, development of resources with knowledge and the transfer of information is beneficial

\footnotetext{
${ }^{1}$ Tom Sander <tomsander@hotmail.de>

2 Biruta.Sloka@lu.Iv

3 Ieva Puke <ieva.puuke@gmail.com>

${ }^{4}$ Anastasija.Vilcina@llu.Iv
} 
for organizations (Marjanovic \& Rothenhoefer, 2014). Individuals acquire information in job advertisements which they need to be successful. Social media provide channels and structure to provide access to knowledge and information. Companies can use this channel to maintain their resources to be successful and to present their resources to individuals (Li \& Bernoff, 2011) (Pentland, 2014). Those organizations can use the advantages of social media for the job advertisements. That supports potential candidates to get access to beneficial and trustful information (Sander, Teh, \& Sloka, 2017). The wrong content in videos can have a negative reaction of the target group and destroy the reputation of companies.

Companies need suiTable employees to be successful and to attract potential candidates to apply to have a future. Videos increase the value of job adds for companies and candidates (Hussain \& Lasage, 2014). This paper concentrates on the opinion of individuals about the benefits of videos in job advertisements. The power of picture and additional content, which can be transferred with videos, is an advantage for the job advertisement. The additional information support the decision of individuals to apply or not to apply (Breaugh, 2008). The amount of information transferred by the video content provides addition emotions. That is only possible with videos and influence individuals. That provides further impressions about the job and organization. The potential candidates get a good overview about potential employer. The video bonds individuals for a longer time on the job advertisement compared with job advertisements without videos. That individuals receive a realistic job preview. That guides to a deeper concentration on the job advertisement and content (Khatri et al., 2015). Individuals provide more attention to job advertisements with videos. However, companies should take into account that $85 \%$ of Facebook video is watched without sound (AmericanPress Institute, 2016). For companies it means the importance of creating videos that can be understood without sound, using captions or text that narrate what is happening on the screen. Also deciding on length of video is important: study of more than 500 thousand videos shows that marketers should keep video ad up to 2 min long. Due to short attention spans and distraction that

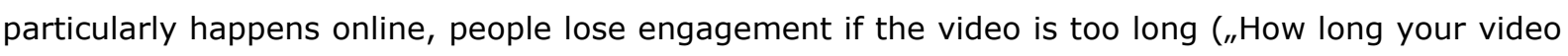
should be", Wistia, 2016). Marketing needs to reach the target group and new technologies provide new opportunities. The new opportunities affect the market. Online advertisement is the future and companies use online job advertisements to reach a large audience and target group. The cost of online advertisements and success is an important factor for companies. The efficiency and effectivity of online job advertisements are important for companies to identify interesting candidates (Ragunathan et al., 2015). The analysis of this communication channel is easily possible and provides new opportunities to companies. The research has been done with a survey and the data have been analysed with descriptive statistics, t-tests, LSD ANOVA and Spearman correlation. The paper presents only the statistically significant results and only the t-test to compare significant results that exist in the two genders. But the descriptive statistic provides a clear tendency and result to provide recommendations for companies to create successful job advertisements and explain the advantages of videos in job advertisements. Employer branding is important for organizations. Videos in job advertisements are a visible signal for potential candidates that companies are very innovative and on the latest technological level. The employer branding is very important to motivate individuals to apply for a position and to keep employees on board. Human resources management needs new channels and tools to be competitive or to have an advantage on the labour market, to be successful in the war for talent (Geffen, 2010; Sivertzen, Ragnhild, Olafsen, \& Olafsen, 2013). The transfer of positive signals is important for the success of the job advertisement to provide a positive image to 
individuals, to be valuable for the company e.g. improving the employer's branding of the company. The companies can present unique selling point to potential candidates to be an attractive employer for the best candidates.

\section{Research results and discussion Online advertisements for recruiting issues}

Online advertisement is an important channel to reach a large audience. The importance of online advertisement is increasing and the technological changes provide new opportunities. The internet is an important communication channel. Social media are daily used by individuals and the user behaviour is an interesting research field (Walker, Feild, Giles, \& Bernerth, 2008). The access to millions of people fast and easily is possible with the internet. Further is it possible to customize information and to provide important information with different media, e.g. videos or audio formats. Online job advertisement is interactive and provides a new kind of communication opportunities to companies to advertise. The tailored information increases the value for the recipients and increases the return of investment for the companies (Colliander \& Dahlen, 2011). The investment in advertisement is more specific. The effectiveness and efficiency of advertisement are increasing with the support of web based solutions. The video content is more easily to understand and the amount of information in a video is more comparable to other mediums. The signal theory is the theoretical background for this research. The signal needs to be clear that the recipient understand the same like the sender. The video can avoid misunderstandings because the information is more precise and detailed, the content and information in videos is more interesting for potential candidates and fulfil their desired kind of medium (Gregory, Meade, \& Thompson, 2013; Spence, 1973). These are important advantages that companies can communicate in their message to attract interest of individuals more successful. The future of online advertisements is different medium with interactive parts. The strength of online job boards is the combination of different kinds of presentation of the information, e.g. audio or visual. That support the advertisement to present the information with different tools and in different types (Howardson \& Behrend, 2014). This increases the attention of individuals. The image of companies is influenced by their advertisement. The use of attractive trendy videos is a clear signal for potential candidates or customer that the company is innovative. Especially young individuals are interested in innovative advertisements and activated with videos in job advertisements (Acarlar \& Bilgiç, 2013). Therefore, the companies use the latest technologies and it increases the reputation and attractiveness for potential candidates and employees of companies and thus is a competitive advantage in the war of talents.

\section{Videos in job advertisements}

The difficulty to identify candidates and to motivate them to apply is very important for companies. They need the best suiTable candidates for their open positions. The demographic change and economic situation influence the labour market. The number of potential candidates is decreasing. The technological development provides new opportunities for companies to present their open positions to a large audience (Sander, 2013; Cober, Brown, Blumental, \& Levy, 2000). Social media is an important tool for advertisement and marketing issues. Job advertisements need to transfer information about the tasks and skills for the position and to inform about the organization. The candidates can find a decision to apply or not to apply. The companies use the job advertisement to attract individuals to apply or use the job advertisements to select candidates (Acarlar \& Bilgiç, 2013). Some companies advertise their positions in English so that only individuals can apply who 
can communicate in English. The job advertisements transfer the image of a company and are an important factor to present the company to a large audience. The interactivities of online job boards can be a positive effect for job advertisements. The agility of job advertisements is a great chance to get more attention for open positions. Job advertisements have different kind of presentations in the internet e.g. printed, audio and video. These new presentation forms provide additional information for the recipient of the advertisements (Sivabalan, Yazdanifard, \& Ismail, 2014). That is a great chance to transfer new kind of information to potential candidates, to present different presentation styles and to transfer more than information. The transfer of emotions is possible with videos. Advertisements include videos as a technical innovation. The videos in advertisements influence the image of companies and present the company as an innovative technical company. Thus, the company is on the latest technical level and of interest for young people. Young people use media in a new way and they are more attracted by videos in online advertisement. Job advertisements are more attractive with videos.

The selection of videos and advertisements can be individualized. The individual get customized information. This information is more of interest for individuals (Baum \& Kabst, 2014). It is possible to provide specialized information to different user with the help of internet tools. The video is very attractive for internet user and can improve the power of the advertisements. The realistic job preview and realistic presentation of companies is possible with videos. Videos can provide realistic information about the company and job descriptions (Backhaus, Backhaus, \& Tikoo, 2014). The content is more detailed and the emotional power of videos has a positive effect on the job advertisements. The video is visible thus enabling audio-visual perception with different sensory organs. The impression of videos is deeper. The mass of content is increasing compared with other tools to advertise open positions. Special effects are possible to attract internet user and to differentiate companies from each other.

Unlike the forced exposure of consumers to traditional TV and radio advertisements where people lack control over presentation of the message, people can choose to view the online video ads with video playback controls when they want and also control the presentation of video ads. According to Lee \& Lee, (2011), viewing of video ads requires active participation by viewers which is triggered by factors such as intention to perform the behaviour, attitude towards performing a behaviour, subjective norm and past behaviour. The content and presentation of video in job advertisement can have negative results. The user and recipients of videos can recognize the content and presentation as infantile or disproportionate. The quality of the videos and technical effects can be perceived as cheap (Relling, Schnittka, Sattler, \& Johnen, 2016). Employees can be embarrassed with the content. That means the content and videos for job advertisements need to be used carefully and responsible.

\section{Research questions to investigate videos in job advertisements}

The statement is that the use of video in job advertisements improves the recruiting process, as this job advertisement transfers more information and thus the content is more authentic. That provides a more realistic job preview for potential candidates (Stone, Deadrick, Lukaszewski, \& Johnson, 2015). The question to the participants in the survey was "What is the value of videos in job advertisements?". There are five answer options. The first option is „I get an improved picture about the company". This item investigates the importance and value of the video in online job advertisements. "The estimation to be suiTable for a company is easier" is the next item. This item proves if the video supports the decision to apply. Thus the candidate has a realistic idea about the 
estimation of the company for candidate's personality. The problem whether candidates get more detailed information about the required skills is investigated within the item "I can image the required skills more superior". But not only the required skills are of interest. The environment of the working place is an important factor for applicants and is tested with the answer item "I get an improved impression about the working place". The answer items provide a good overview about the benefits of videos in job advertisements. Thus, the video is a part of the job advertisement.

\section{Method and demographic factors}

The investigation of online job advertisements with video content attracts? participants who are able to use the internet and the participants should have experience with employment seeking situation. The online survey was provided in April - May 2017 to 990 potential participants and the paper used up to 316 responses for the evaluation of the research questions. The online survey is suiTable for this research because individuals have to have access to the internet to use the internet to identify job advertisements with videos (Evans and Mathur, 2005; Wright, 2005). The research project was supported by University of Ludwigshafen. The a six-point Likert scale from one for "full agreement" to six for "full disagreement" was used in the survey. The demographic data are presented in Table 1.

Table 1

Demographic data of the respondents, share in \%, $n=275$

\begin{tabular}{|c|c|c|c|c|c|}
\hline Social status & $\begin{array}{l}\text { Share } \\
\text { (in \%) }\end{array}$ & Age distribution & $\begin{array}{l}\text { Share } \\
\text { (in \%) }\end{array}$ & Education & $\begin{array}{l}\text { Share } \\
(\text { in \%) }\end{array}$ \\
\hline Employed & 48.9 & Under 18 years & 0.4 & \multirow{2}{*}{ School degree } & \multirow{2}{*}{25.7} \\
\hline Unemployed & 0.7 & $18-20$ years & 9.1 & & \\
\hline Student & 40.9 & $21-25$ years & 40 & \multirow{2}{*}{$\begin{array}{l}\text { Apprenticeship - } \\
\text { practical training }\end{array}$} & \multirow[b]{2}{*}{42.6} \\
\hline $\begin{array}{l}\begin{array}{l}\text { School } \\
\text { student }\end{array} \\
\end{array}$ & 7.7 & $26-30$ years & 20.4 & & \\
\hline Retired & 1.8 & $31-36$ years & 9.5 & \multirow{2}{*}{$\begin{array}{l}\text { University degree - } \\
\text { three year program }\end{array}$} & \multirow{2}{*}{19.9} \\
\hline$n=274$ & 100 & $36-40$ years & 2.2 & & \\
\hline & & $41-45$ years & 1.1 & \multirow{2}{*}{$\begin{array}{l}\text { University degree - } \\
\text { more than three year } \\
\text { program }\end{array}$} & \multirow{2}{*}{9.6} \\
\hline Gender & & $46-50$ years & 4.3 & & \\
\hline Men & 33.3 & $51-55$ years & 6.8 & \multirow{2}{*}{ PhD or higher degree } & \multirow{2}{*}{2.2} \\
\hline Women & 66.7 & Over 56 & 6.2 & & \\
\hline$n=273$ & 100 & $\mathrm{n}=275$ & 100 & $\mathrm{n}=272$ & 100 \\
\hline
\end{tabular}

Source: author's calculations based on Tom Sander's conducted survey

There are $69.5 \%$ of the survey participants 30 years old or younger. Young individuals are trained and experienced with online forms and most of them need to investigate job opportunities in the near future or have searched employment in the near history. Young individuals are trained and experienced with online videos. Their consumer behaviour is supported by video content and they believe that online videos are available to collect further information.

\section{Research results for videos in job advertisements}

The results of the items for the questions are very similar. The best result with a median of two is the item "I get an improved picture about the company". All other items have the median three. That is weak tendency to completely correctly. That means videos in job advertisements in general have a positive influence and beneficial issue for employment seeking individuals. This result is supported by the mode three for the item "The estimation to be suiTable for a company is more easily" and mode two for all other items. The results in detail are presented in Table 2. 
Main statistical indicators of answers for the question "What is the value of videos in job advertisements?"

\begin{tabular}{|l|c|c|c|c|}
\hline & $\begin{array}{c}\text { I get an improved } \\
\text { picture about the } \\
\text { company }\end{array}$ & $\begin{array}{c}\text { The estimation to be } \\
\text { suiTable for a } \\
\text { company is more } \\
\text { easily }\end{array}$ & $\begin{array}{c}\text { I can image the } \\
\text { required skills } \\
\text { more superior }\end{array}$ & $\begin{array}{c}\text { I get an improved } \\
\text { impression about the } \\
\text { working place }\end{array}$ \\
\hline $\mathbf{n}$ & 319 & 316 & 319 & 319 \\
\hline Mean & 2.81 & 3.17 & 3.07 & 2.87 \\
\hline Median & 2 & 3 & 3 & 3 \\
\hline Mode & 2 & 3 & 2 & 2 \\
\hline $\begin{array}{l}\text { Standard } \\
\text { deviation }\end{array}$ & 1.426 & 1.404 & 1.498 & 1.420 \\
\hline
\end{tabular}

Evaluation scale 1-6, where 1 - full agreement; 6-full disagreement Source: author's calculations based on Tom Sander's conducted survey

All items have over $63 \%$ on the first three stages on the evaluation scale. The most consent on the first three stages with $72.4 \%$ has the item "I get an improved impression about the working place". On the second place with $69.9 \%$ is the item "I get an improved picture about the company". The third place with $64.7 \%$ on the first three stages has the item "I can image the required skills more superior". The item "The estimation to be suiTable for a company is more easily" is on the first three stages is $63.7 \%$. The distribution of the selection provides a clear tendency to "completely correctly" and supports the statement that videos are a beneficial asset for job advertisements. The items "get an improved picture about the company" and "the estimation to be suiTable for a company is more easily" have significant differences between male and female. That is the only demographic factor which has a significant difference in evaluations by male and female respondents. All other demographic factors do not have a significant result or significant correlation coefficient. The results of the t-test are presented in Table 3.

Table 3

\section{Main statistical indicators of t-test for the differencies in answers of men and women}

\begin{tabular}{|c|c|c|c|c|c|c|c|c|}
\hline & & \multicolumn{2}{|c|}{$\begin{array}{l}\text { Levene's Test } \\
\text { for Equality of } \\
\text { Variances }\end{array}$} & \multicolumn{5}{|c|}{ t-test for Equality of Means } \\
\hline & & $\mathbf{F}$ & Sig. & $\mathbf{t}$ & df & $\begin{array}{l}\text { Sig. (2- } \\
\text { tailed) }\end{array}$ & $\begin{array}{c}\text { Mean } \\
\text { difference }\end{array}$ & $\begin{array}{l}\text { Std. Error } \\
\text { Dif. }\end{array}$ \\
\hline \multirow{2}{*}{$\begin{array}{l}\text { I get an } \\
\text { improved } \\
\text { picture about } \\
\text { the company }\end{array}$} & $\begin{array}{l}\text { Equal } \\
\text { variances } \\
\text { assumed }\end{array}$ & 0.555 & 0.457 & 2.373 & 270 & 0.018 & 0.435 & 0.183 \\
\hline & $\begin{array}{l}\text { Equal } \\
\text { variances not } \\
\text { assumed }\end{array}$ & & & 2.335 & 170 & 0.021 & 0.435 & 0.186 \\
\hline \multirow{2}{*}{$\begin{array}{l}\text { The estimation } \\
\text { to be } \\
\text { suiTable for a } \\
\text { company is } \\
\text { more easily }\end{array}$} & $\begin{array}{l}\text { Equal } \\
\text { variances } \\
\text { assumed }\end{array}$ & 0.371 & 0.543 & 2.276 & 268 & 0.024 & 0.417 & 0.183 \\
\hline & $\begin{array}{l}\text { Equal } \\
\text { variances not } \\
\text { assumed }\end{array}$ & & & 2.284 & 179.8 & 0.024 & 0.417 & 0.182 \\
\hline
\end{tabular}

Evaluation scale 1-6, where 1 - full agreement; 6-full disagreement, $n=319$

Source: author's calculations based on Tom Sander's conducted survey

The differences in evaluations between men and women are visible in the diagrams below. Men have $60 \%$ on the first three steps and women have $74 \%$ on the first three stages for the item "I get an improved picture about the company". That means women have a stronger tendency to "completely correctly". The second item is the "estimation to be suiTable for a company is easier" with $55 \%$ for men on the first three stages and women in $66 \%$ of answers on the first three stages. 
Women have for both items the majority on the first three stages. It is important to point out that men and women have different user behaviour and benefits. But all other demographic factors do not have any influence on the benefits of videos in job advertisements with a significant result. The research tested the demographic factors with cross tables, LSD ANOVA and Spearman correlation.

\section{Conclusions, proposals, recommendations}

1) Videos are recognized as a valuable source for realistic information about employer and jobs. This support the realistic job preview. The videos improve the return of investment of the job advertisements for companies and potential candidates. The companies get only well informed applicants and prepared employees with a realistic impression about the company. That improves the retention rate and satisfaction of the future employees.

2) The general tendency of the participants is that videos are beneficial with their additional information about jobs and employer. Potential candidates can use this information to decide to apply or not to apply. That is an important advantage for companies to receive suiTable applications and to attract the right candidate. The videos provide a realistic job preview and are an attractive medium for young individuals.

3) The difference between demographic groups exists only for two items for the gender. All other demographic factors do not influence the advantage of videos in job advertisements. That means videos and their content is beneficial for anybody. Independent from the researched demographic factors is the interest in videos in job advertisements. That means the results are valid for all groups without any differences between demographic groups.

4) The importance of information and suiTable channels is researched within this paper. Individuals need information to find a decision and videos can provide information that is needed to find a decision for a job and employer. Thus companies can use this medium to be attractive for potential candidates and motivate candidates to apply for a job.

5) Further research needs to investigate the kind of content which is required to successfully attract applicants to be interested in the employer. The research needs to investigate the influence of videos in job advertisements in detail to decide to apply or not to apply.

\section{Bibliography}

1. Acarlar, G., Bilgiç, R. (2013). Factors Influencing Applicant Willingness to Apply for the Advertised Job Opening: the Mediational Role of Credibility, Satisfaction and Attraction. The International Journal of Human Resource Management, Volume 24, Issue 1, pp. 50-77.

2. Animoto Online and Social Video Marketing Study (2015). Retrieved: https://animoto.com/blog/business/video-marketing-cheat-sheet-infographic/ Access: 15.11.2018.

3. Backhaus, K., Backhaus, K., Tikoo, S. (2014). Conceptualizing and researching employer branding. Career Development International, Volume 9, Issue 5, pp. 501-517.

4. Baum, M., Kabst, R. (2014). The Effectiveness of Recruitment Advertisements and Recruitment Websites: Indirect and Interactive Effects on Applicant Attraction. Human Resource Management, Volume 53, Issue 3, pp. 353-378.

5. Breaugh, J.A. (2008). Employee recruitment: Current knowledge and important areas for future research. Human Resource Management Review, Volume 18, Issue 3, pp. 103-118.

6. Cober, B.R.T., Brown, D.J., Blumental, A.J., Levy, P.E. (2000). The Guest for the Qualified Job Surfer: it's Time the Public Sector Catches the Wave. Public Personnel Management, Volume 29, Issue 4, pp. 479-496.

7. Colliander, J., Dahlen, M. (2011). Following the Fashionable Friend: The Power of Social Media - Weighing the Publicity Effectiveness of Blogs Versus Online Magazines. Journal of Advertising Research, Volume 51, Issue 1 , pp. $313-320$.

8. Digital Content Newfronts: Video Ad Spend Study (2017). Interactive Advertising Bureau, Retrieved: https://www.iab.com/wp-content/uploads/2017/05/2017-IAB-NewFronts-Video-Ad-Spend-Report.pdf Access: 15.11.2018.

9. Evans, J.R., Mathur, A. (2005). The value of online surveys. Internet Research, Volume 15, Issue 2, pp. 195-219. 
10. Fishman E. (2016) How Long Your Video Should be. Wistia. Retrieved: https://wistia.com/blog/optimalvideo-length Access: 12.10.2018.

11. Geffen, C. Van. (2010). The Meaning of Employer Branding. In 12th Twente Student Conference on IT.

12. Global Video Index (2017). Retrieved: www.ooyala.com Access: 12.12 .2018

13. Gregory, C.K., Meade, A.W., Thompson, L.F. (2013). Understanding Internet Recruitment via Signalling Theory and the Elaboration Likelihood Model. Computers in Human Behavior, Volume 29, Issue 5, pp. 19491959.

14. Howardson, G.N., Behrend, T.S. (2014). Using the internet to recruit employees: Comparing the Effects of Usability Expectations and Objective Technological Characteristics on Internet Recruitment Outcomes. Computers in Human Behavior, Volume 31, Issue 1, pp. 334-342.

15. How Long Your Video Should Be (2016). Wistia. https://wistia.com/blog/optimal-video-length Access: 10.10.2018.

16. Hussain, D., Lasage, H. (2014). Online Video Advertisement Avoidance: Can Interactivity Help? Journal of Applied Business Research, Volume 30, Issue 1, pp. 43-49.

17. Khatri, C., Chapman, S.J., Glasbey, J., Kelly, M., Nepogodiev, D., Bhangu, A., Fitzgerald, J.E. (2015). Social Media and Internet Driven Study Recruitment: Evaluating a New Model for Promoting Collaborator Engagement and Participation. PLOS ONE, Volume 10, Issue 3, pp. 1-11.

18. Li, C., Bernoff, J. (2011). Groundswell, Winning in a World Transformed by Social Technologies. Boston: Harvard Business Review Press.

19. Lee, J., Lee, M. (2011). Factors Influencing the Intention to Watch Online Video Advertising. Cyberpsychology, Behavior, and Social Networking, Volume 14, Issue 10, pp. 619-624.

20. Marjanovic, O., Rothenhoefer, M. (2014). Improving Knowledge-Intensive Business Processes through Social Media. In Twentieth Americas Conference on Information Systems (pp. 1-11).

21. Measure of Video Ad Spending (2017). Retrieved: https://www.emarketer.com/Article/Measure-of-VideoAd-Spending-Shows-Sharp-Increase/1015793 Access: 23.10.2018.

22. Pentland. (2014). Social Physics. New York, New York, USA: Penguin Books.

23. Ragunathan, T., Battula, S. K., Jorika, V., Mounika, C., Sruthi, A.U., Vani, M.D. (2015). Advertisement Posting Based on Consumer Behavior. Procedia Computer Science, Volume 50, pp. 329-334.

24. Relling, M., Schnittka, O., Sattler, H., Johnen, M. (2016). Each Can Help or Hurt: Negative and Positive Word of Mouth in Social Network Brand Communities. International Journal of Research in Marketing, Volume 33, Issue 1, pp. 42-58.

25.Sander, T. (2013). New Circumstances for the Labor Market under the Consideration of Social Media. Communications of Global Information Technology, Volume 5, pp. 41-52.

26. Sander, T., Teh, P.L., Sloka, B. (2017). Your Social Network Profile Reveals You. International Journal of Web Information Systems, Volume 13, Issue 1, pp. 14-24.

27. Sivabalan, L., Yazdanifard, R., Ismail, N.H. (2014). How to Transform the Traditional Way of Recruitment into Online System. International Business Research, Volume 7, Issue 3, pp. 178-186.

28. Sivertzen, A.-M., Ragnhild, E., Olafsen, N., Olafsen, A. H. (2013). Employer Branding: Employer Attractiveness and the use of Social Media. Journal of Product \& Brand Management, Volume 22, Issue 7, pp. 473-483.

29.Spence, M. (1973). Job Market Signalling. The Quarterly Journal of Economics, Volume 87, Issue 3, pp. 355-374.

30.Stone, D.L., Deadrick, D.L., Lukaszewski, K.M., Johnson, R. (2015). The Influence of Technology on the Future of Human Resource Management. Human Resource Management Review, Volume 25, Issue 2, pp. 216-231.

31.U.S. Desktop Online Video Rankings (2015-2016). Retrieved: www.comscore.com Access: 27.11.2018.

32. Walker, H.J., Feild, H.S., Giles, W.F., Bernerth, J.B. (2008). The Interactive Effects of Job Advertisement Characteristics and Applicant Experience on Reactions to Recruitment Messages. Journal of Occupational and Organizational Psychology, Volume 81, Issue 4, pp. 619-638.

33. Wright, K. B. (2005). Research in Internet-Based Populations: Advantages and Disadvantages of Online Survey Research, Online Questionnaire Authoring Software Packages, and Web Survey Services. Journal of Computer-Mediated Communication, Volume 10, Issue 3, pp. 1-15. 